\title{
República dos antigos,
}

\section{república dos modernos}

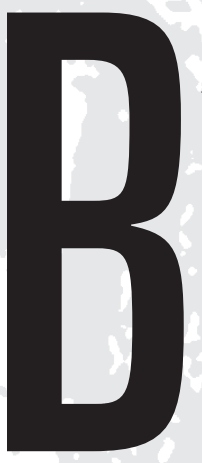

enjamin Constant perseguiu durante toda sua vida o sucesso e o reconhecimento muitas vezes à custa de sacrifícios pessoais e de renúncias, que no período pós-revolucionário, na França, nem sempre lhe granjearam a simpatia e a compreensão de seus contemporâneos. Dividido entre o desejo de atuar na cena pública de forma contundente e a vontade de legar à posteridade uma obra de fôlego sobre matérias tão complexas quanto história das religiões e política, ele acabou se lançando em projetos conflitantes, que raramente

NEWTON BIGNOTO é professor de Filosofia da UFMG e autor de Origens do Republicanismo Moderno (Editora da UFMG). atingiram o fim almejado. Uma boa parte de suas reflexões foi elaborada durante o período de exílio forçado no início do século XIX, quando sua ligação com 


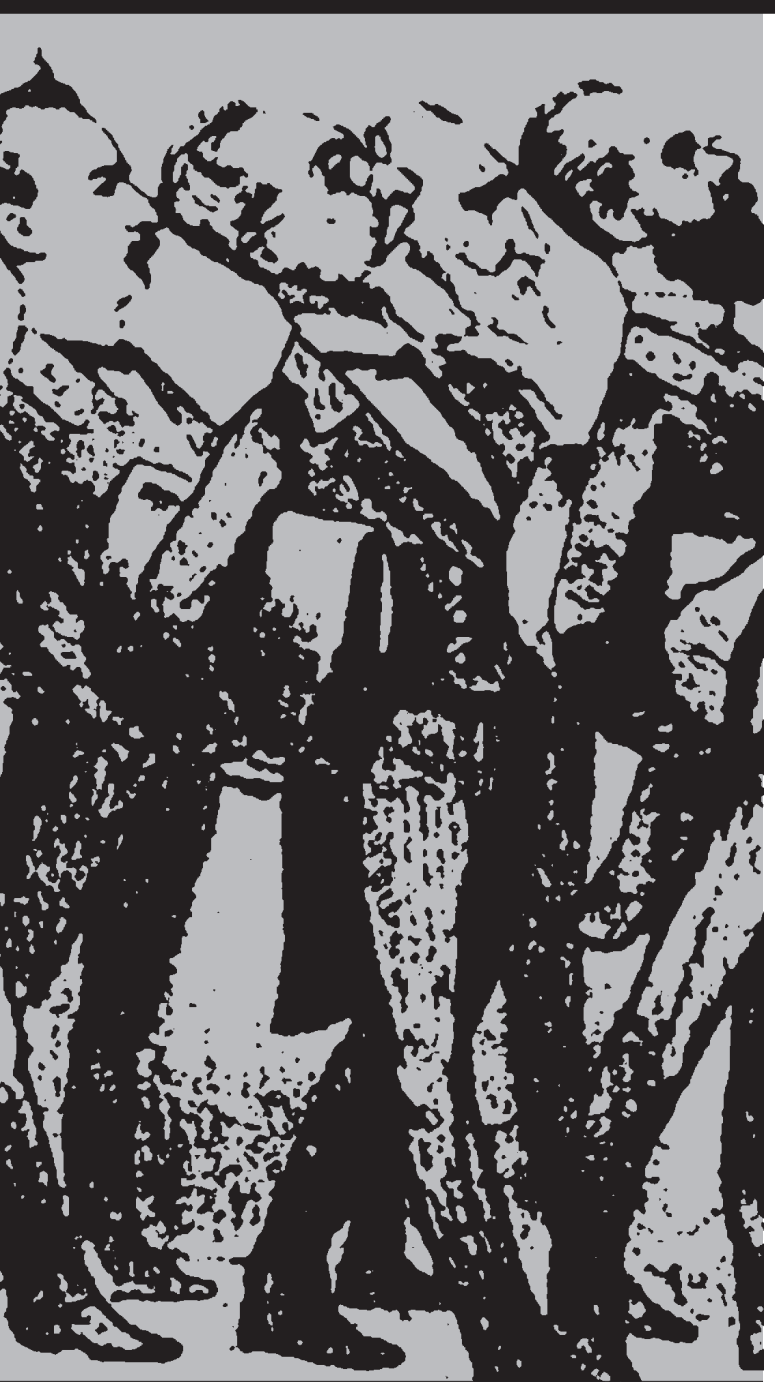

Madame de Staël e sua oposição às políticas napoleônicas lhe custaram um afastamento do mundo público. Desse maciço original ele retiraria boa parte de seus escritos posteriores, copiando, cortando pedaços inteiros ou simplesmente reescrevendo trechos originalmente destinados a outros textos. Constant acabou, entretanto, construindo uma obra que, apesar de guardar a marca das circunstâncias que a viram nascer, revela uma surpreendente coe- rência no tocante a seus princípios fundamentais. Se, como muitos dos pensadores liberais do século XIX francês, ele foi objeto de um esquecimento voluntário e mesmo desdenhoso por parte dos que se dedicaram a compreender o nascimento da modernidade política, isso não impediu suas idéias de influenciarem decididamente os debates que opuseram pensadores liberais contemporâneos a socialistas e mais recentemente a republicanos e comunitaristas ( I)

O objetivo deste texto não é o de oferecer uma visão de conjunto da obra de Constant e nem mesmo o de mostrar sua influência na formação do pensamento liberal. Nossa intenção é recuperar alguns argumentos centrais em seus escritos, que tiveram um papel decisivo nos debates contemporâneos sobre a natureza e a finalidade das sociedades democráticas, e analisar o alcance e as bases de suas afirmações sobre a natureza dos regimes republicanos da Antigüidade e aqueles derivados das experiências revolucionárias modernas. Nosso alvo será a famosa distinção entre a liberdade dos antigos e a liberdade dos modernos, apresentada por Constant como uma das muitas inovações de suas reflexões políticas
Ver a esse respeito o texto ins pirado de Charles Taylor, "Propósitos Entrelaçados: o Debo te liberal-Comunitório" lin C. Taylor, Argumentos Filosóficos, São Paulo, Loyola, 2000, pp 197-220| 
20 principal texto no qual ele trata do assunto é uma confe rência pronunciada em 1819 no Athénée: "De la Liberté de Anciens Comparée à Celle des Modernes". Como veremos tro ta-se de uma idéia recorrente em seus escritos, que taz parte do núcleo de sua concepção liberal da política. Nesse texto seguiremos a edição parcia das obras de Constant organ zada por Marcel Gauchet: Benjamin Constant, De la Liberté chez les Modernes, Paris, Hachette, 1980

3 Benjamin Constant, "De la Liberté des Anciens Comparée à Celle des Modernes", op. cit. p. 495.

4 Idem, ibidem, p. 502

5 Não deixa de ser curioso que a famosa definição da liberdade como ausência de constrangimento, presente no começo do capítulo XXI da segunda parte do Leviatã de Hobbes, tenha servido para fundamenta uma concepção de sociedade na qual o governo tem um lugar pouco significativo na administração da vida pública. Deixaremos de lado, no entanto, esse problema uma vez que ele não concerne o núcleo de nosso argumento (Thomas Hobbes, Leviathan. Harmondsworth Penguin Books, 1985, pp. 261 74).

6 Raymond Aron, apud P. Manent Les Libéraux Paris, Gallimard, 2001, p. 846

7 I. Berlin, "Deux Conceptions de a Liberté", in Eloge de la Liberté, Paris, Calmann-Lévy, 1988, pp. $167-218$

8 Idem, ibidem, p. 21 l em vários de seus escritos (2). Não nos interessa, por enquanto, verificar se a reivindicação de originalidade procede, mas simplesmente constatar que esse mérito foilhe atribuído por muitos de seus seguidores, e que suas idéias continuam a influenciar aqueles que defendem a democracia liberal representativa como única forma coerente de organização da vida política nas sociedades capitalistas modernas.

Procuremos, no entanto, precisar nosso problema. Constant opera em seu escrito de 1819 uma separação entre o mundo antigo e o mundo moderno fundada no fato de que a maneira como concebiam a liberdade era diferente e inconciliável. Os antigos, segundo ele, exerciam uma soberania direta, deliberando sobre assuntos variados como a guerra contra povos estrangeiros, a gestão das magistraturas e a promulgação das leis. A consequiênciaé que "admitiam como compatível com ela (a liberdade) a submissão completa do indivíduo à autoridade do todo" (3). Em outra direção, "o objetivo dos modernos é a segurança dos privilégios privados; e eles chamam liberdade as garantias concedidas pelas instituições a esses privilégios" (4). Deixemos por um instante Constant de lado, para observarmos a recepção de suas idéias para além de seu tempo.

No correr do século XX vários pensadores liberais, como Raymond Aron e F. A Hayek, fizeram da definição de liberdade como ausência de constrangimento - definição que remonta a Hobbes e não a Constant (5) - a pedra de toque de um combate levado a cabo contra todas as formas de governo que trazem para o centro do debate a participação direta dos homens na construção da vida política cotidiana e na definição das medidas a serem tomadas contra tudo o que é sentido como ameaça à sobrevivência do corpo político. O que esses pensadores retiveram da argumentação de Constant foi sobretudo a oposição a toda e qualquer forma de governo que pareça depender de um cidadão ativo e militante para existir. Como resume muito bem Aron, ao manifestar sua concordância com os princípios liberais de Hayek, "o objetivo de uma sociedade livre deve ser o de limitar o mais possível o governo dos homens pelos homens e de aumentar o governo dos homens pelas leis" (6). É claro que nenhum dos dois desconsiderava as dificuldades que envolvem a definição do que é uma sociedade governada pelas leis e não pelos homens, mas isso não os impedia de se opor a qualquer interferência na vida dos cidadãos que possa ser atribuída diretamente a um homem ou a um grupo de homens cujos interesses não sejam expressos pelas vias previamente acordadas por todos.

Em que pese, no entanto, a importância e a força dos argumentos de muitos pensadores liberais, poucos escritores foram mais bem-sucedidos em defender a superioridade da concepção de liberdade negativa sobre a concepção de liberdade positiva do que Isaiah Berlin. Num artigo célebre "Duas Concepções da Liberdade" (7)-ele retoma de forma direta o pensamento de Benjamin Constant. Na verdade, o pensamento de Berlin é pouco original no que diz respeito às grandes linhas da tradição liberal, mas é importante para a compreensão dos fios de continuidade entre os grandes teóricos dessa tradição e seus defensores na atualidade. No que diz respeito à liberdade, ele não hesita em usar as concepções do século XIX sem introduzir mediações. Referindo-se a um grupo de teóricos que inclui Constant, Mill e mesmo Tocqueville, ele afirma: "Durante todo o século XIX, os pensadores liberais sustentaram que se a liberdade não contém limites ao poder de alguém de me obrigar a fazer o que não quero, então, independente do ideal em nome do qual eu fui constrangido, eu não sou livre. Para eles, uma doutrina da soberania absoluta era uma doutrina da tirania" (8).

Para Berlin uma sociedade só pode ser dita livre se respeitar pelo menos dois princípios. O primeiro, que coincide com o enunciado de Hayek, garante em todas as circunstâncias o predomínio das leis sobre a vontade dos homens e dos governantes arbitrários. O segundo garante a existência de limites invioláveis dentro dos quais os homens podem se sentir seguros quanto a qualquer comando emanado das leis ou de 
outros homens. Essa limitação, ou salvaguarda, impõe restrições claras à prática de atos bárbaros que, em qualquer circunstância, seriam desumanizadores daqueles que os perpetrassem. Esses limites comportam, por exemplo, a interdição da aplicação retroativa de uma lei nova para qualquer acusado de um crime, a negação de qualquer condenação sem julgamento, a suspensão de perseguições a minorias ou a dissidentes políticos, a interdição da tortura e da delação entre parentes próximos. Ao analisarmos esses dois princípios não teríamos dificuldade em conferir-lhes validade e em reconhecê-los como esteios fundamentais da democracia contemporânea. O problema surge no momento em que, para defender sua concepção de liberdade, Berlin enuncia a posição dos que considera como seus adversários: "encontramo-nos aqui no oposto do que é buscado pelos partidários da liberdade positiva. Uns desejam restringir a autoridade enquanto tal; outros que ela esteja em suas mãos. O problema é capital, pois não se trata de duas interpretações diferentes de um mesmo conceito, mas de dois pontos de vista opostos e mesmo inconciliáveis com relação aos fins da existência humana" (9).

Ao enunciar com cores tão radicais a oposição entre os defensores das duas formas de liberdade, Berlin deixa entrever o coração de sua argumentação. Na modernidade apenas a liberdade negativa é compatível com uma sociedade livre e sadia. Os que defendem qualquer outra concepção aproximam-se da barbárie que eclodiu em vários momentos da história recente do Ocidente. Nessa lógica, é o mesmo o perigo que ronda as concepções republicanas inspiradas em modelos do passado, o período jacobino da Revolução Francesa, a Revolução Russa, o stalinismo e outros acontecimentos dos séculos XIX e XX. Os riscos são a instauração da barbárie e a perda da liberdade. A estratégia argumentativa do intérprete liberalé, pois, a de fazer amálgama de todas as experiências que não reconhecem a verdade da definição da liberdade como ausência de constrangimento como a única legítima. Berlin não poderia ser mais claro quando afirma que o verdadeiro conflito se desenrola no campo das concepções dos fins da vida associativa. De maneira explícita, ele diz a seu leitor que a única sociedade livre é aquela organizada segundo os princípios liberais

Não podemos pretender que a argumentação dos pensadores liberais contemporâneos siga sempre o modelo sugerido por Berlin e que todos realizem a mesma operação de amálgama entre correntes diversas de pensamento. Partindo de um outro ponto de vista, Taylor caracteriza melhor o debate atual quando mostra que existe sim uma disputa entre concepções diferentes de sociedade. Para ele, pensar a liberdade nos moldes da participação-liberdade em sentido positivo - implica recusar um modelo baseado na centralidade do indivíduo, para propugnar uma sociedade orientada por valores coletivos, mas isso nada tem a ver com as diversas experiências totalitárias e ditatoriais, que marcaram o cenário dos últimos dois séculos (10), ou mesmo com o jacobinismo, que está ma mira de Berlin, quando faz suas críticas (11). O que gostaríamos de ressaltar é que a distinção entre as duas formas de liberdade é um aspecto fundamental da concepção liberal contemporânea de sociedade e que, independentemente dos abusos cometidos em sua utilização, ela não pode ser descartada se quisermos compreender uma das facetas mais importantes das disputas teóricas atuais, sobretudo aquelas que opõem liberalismo e republicanismo.

É nossa convicção que Benjamin Constant influenciou de forma decisiva o debate em seu século, e que legou para a posteridade uma visão do problema que foi definitiva para a consolidação da tradição liberal. Por isso, vale a pena retornar a seus textos para entendermos o momento de formação de uma maneira de argumentar que ajudou a construir não apenas a identidade liberal, mas também a idéia que muitos teóricos têm daqueles que tomaram caminhos diferentes dos seus. Se certamente não podemos correr o risco de conceder a Constant, no plano da história das idéias, mais do que ele merece, também não pode-
9 Idem, ibidem, p. 213

10 Charles Taylor, "Propósitos En trelaçados: o Debate Libera Comunitário", op. cit. PP. $198-9$

1 I. Berlin, "Deux Conceptions d la Liberté", op. cit., p. 209. 
12 Benjamin Constant, "De l'Esprit de Conquête et de I'Usurpation", in De la Liberté chez les Modernes, op. cit., p. 182.

13 ldem, ibidem.

14 Marcel Gauchet observa, na notas da obra de Constant, que Madame de Staël, em seu Circonstances Actuelles qui Peuvent Terminer la Révolution, de 1798, já notava a diferenca que separava os antigos dos modernos no que toca à libe dade. Para ela, como para seu amigo mais tarde, o recurso a uma forma de liberdade incompatível com os tempos moder nos era um perigo a ser evitado a qualquer preço (Benjamin Constant, De la Liberté chez les Modernes, op. cit., p. 630).

15 "L'avantage que procurait au peuple la liberté, comme les anciens la concevait, c'éta d'être de fait au nombre des gouvernants; avantage réel plaisir à la fois flatteur etsolide (Benjamin Constant, "Del'Esprit de Conquête et de |'Usurpation", op. cit., p. 184).

$16 \mathrm{ldem}$, ibidem.

17 ldem, ibidem.

18 ldem, ibidem.

19 Marcel Gauchet, "Preface", in Benjamin Constant, De la Liberté chez les Modernes, op. cit., p. 43 mos deixar de reconhecer que, pelo menos no que diz respeito à caracterização dos problemas das sociedades modernas pela ótica da questão da liberdade, ele alcançou o sucesso que desejou durante toda sua existência.

Vamos retornar a nosso autor consultando inicialmente um de seus escritos, antes de retomarmos a leitura de trechos de sua célebre conferência. Trata-se do "De 1'Esprit de Conquête et de 1'Usurpation", texto que, segundo o autor, pretende analisar duas pragas de seu tempo num momento em que a Europa sofria com os tumultos provocados pelas guerras e pela usurpação do poder por alguns homens, que Constant reputava serem meros aventureiros. Os capítulos que nos interessam mais de perto se encontram na segunda parte, dedicada à usurpação.

$\mathrm{Na}$ apresentação do sexto capítulo da parte referida, nosso autor enuncia o que será o núcleo de sua argumentação: “A liberdade que foi apresentada aos homens no final do século passado foi tomada de empréstimo das repúblicas antigas" (12). A partir desse ponto a oposição entre o mundo antigo e o mundo moderno será parte integrante de toda a análise elaborada por Constant. Insistir nas diferenças entre o comportamento dos antigos e o que lhe parecia constituir a modernidade política nascente foi sua maneira de expor a recusa de tudo o que se seguiu à Revolução. Olhando para os anos finais do século XVIII e para a Europa devastada pelas guerras napoleônicas, ele foi levado a concluir que o engajamento direto dos homens na ação política compôs o quadro de um terrível engano histórico. "Essa liberdade", diz ele, "compunha-se muito mais da participação ativa no poder coletivo do que no gozo suave da independência individual" (13).

O início do capítulo não deixa dúvidas quanto à intenção de Constant. Retomando um argumento presente em Madame de Staël desde o final do século (14), ele parece disposto a demonstrar que o esforço para conduzir os homens a participar ativamente da vida pública contraria a marcha do progresso das civilizações. De fato, a liber- dade da qual gozavam os antigos lhes trazia um prazer "sólido" (15), mas esse prazeré experimentado na modernidade quando nos fazemos representar. Essa alteração nos "prazeres" se deve ao fato de que os antigos "tinham mais prazer em sua existência pública e menos em sua existência privada" (16). Quanto aos modernos, “quase todos seus prazeres estão na esfera privada: a imensa maioria, sempre excluída do poder, atribui um valor muito pequeno à sua existência pública" (17).

As linhas gerais do argumento de Constant são bastante conhecidas até mesmo pelo sucesso que alcançaram entre os pensadores liberais de nossos dias. Seria interessante, no entanto, continuar a analisar seu texto à luz dos debates imediatos que o inspiraram e dos pressupostos que nosso autor esposa. Em primeiro lugar, é necessário observar que ele depende de uma noção de progresso muito bem assentada para fazer valer suas razões. No curso de seu escrito, ele fala sem ambigüidade que “os progressos da civilização, a tendência comercial da época, a comunicação dos povos entre eles, multiplicaram ao infinito os meios de felicidade particular" (18). A crença na marcha da civilização européia e no progresso não tem nada de escandaloso no momento em que Constant escreve. Ao contrário, talvez fosse mais correto pensar que ele se serve de um lugar-comum de seu tempo para fazer valer suas idéias junto a um público que não era, a princípio, simpático à suas concepções.

Mas é preciso estar atento para o funcionamento de seu pensamento e perguntar se podemos nos servir de suas conclusões sem adotarmos, como ele, a idéia de que as civilizações caminham inexoravelmente para um abandono progressivo das organizações do passado em favor de uma nova ordenação social. Com isso não pretendemos deixar de lado o fato observado por Gauchet de que Constant soube como poucos perceber a constituição de uma modernidade em tudo diferente de um passado que muitos autores continuavam a venerar (19). Contrariamente a muitos de seus adversários, ele soube enxergar no indivíduo um ele- 
mento indissociável dos processos que conduziam os homens a um novo tempo. Nesse sentido, viu a diminuição do desejo de participação como uma das marcas de afirmação de uma sociedade baseada na vida privada e no gozo pessoal de vantagens materiais. O que não podemos deixar de ladoé que Constant precisou adotar uma visão progressiva da história para chegar à suas conclusões. Sem a noção de progresso nãoé possível afirmar que os antigos foram deixados para trás de forma definitiva. Esquecer esse aspecto da demarche de Constant corresponde a abandonar um elemento que contribui para torná-la coerente e não um detalhe marginal em seu procedimento analítico. Recusando uma concepção cíclica do tempo, ainda operante em pensadores do começo do século XVIII, em favor de uma concepção linear, ele abre as portas para a afirmação da ultrapassagem definitiva do passado, inclusive no tocante à maneira como os homens organizavam a vida política.

Sua visão da Antigüidade, entretanto, nada tinha de original. Ainda no capítulo que estamos analisando, ele afirma que uma das dificuldades para nos servirmos dos modelos gregos e romanos residia no fato de que o tamanho reduzido do território das pequenas repúblicas antigas é que permitia a seus cidadãos participar direta e cotidianamente das decisões mais importantes da vida política de sua cidade (20). Ora, essa era uma observação que podia ser encontrada em quase todos os autores que pensaram a política no século XVIII, de Montesquieu, passando pela Encyclopedie de Diderot et d'Alembert, até Rousseau. $\mathrm{Na}$ verdade Constant faz uma afirmação que apenas mascara o problema que atormentou vários autores, a saber, se seria possível constituir uma democracia ou uma república nos Estados nacionais modernos nos mesmos moldes das cidades antigas. Independente das convicções de autores como Montesquieu ou Rousseau, seria muito difícil encontrar, no curso do século XVIII, alguém disposto a defender a simples imitação dos antigos como modelo de conduta política. O que devemos nos per- guntar é por que Constant repetiu a mesma observação ao longo de sua obra.

Ao descrever o cidadão antigo, nosso autor retoma mais uma vez lugares-comuns de sua época. Os cidadãos das antigas repúblicas aceitavam sacrificar sua "independência privada" para garantir sua importância política. Referindo-se aos séculos republicanos romanos, ele diz: “o cidadão se transformou em escravo da nação da qual ele fazia parte" (21). A oposição central continua a ser aquela entre o cidadão ativo e o indivíduo dedicado à vida privada nos tempos modernos. Um detalhe, no entanto, chama a atenção na argumentação de nosso autor. Ao falar das repúblicas antigas e do controle que exerciam sobre seus cidadãos, ele insiste em excluir Atenas da lista, recorrendo para isso a uma menção à obra de Xenofonte e Isócrates. Se tomarmos a afirmação apenas do ponto de vista da história da Antigüidade, veremos que ela não se sustenta. Dizer que Atenas foi uma cidade de exceção no mundo antigo não implica demarcar o território de sua originalidade. Além do mais, a afirmação de Constant não faz jus nem mesmo às idéias correntes de seu tempo, que colocavam Atenas como um dos exemplos mais claros do desenvolvimento das repúblicas no passado, como prova o verbete "République" da Encyclopedie de Diderot et d'Alembert (22). Além do mais, basta recorrer ao texto de sua conferência de 1819 para constatar que pelo menos algumas instituições tipicamente atenienses estão listadas entre os absurdos que os legisladores modernos pretendiam copiar (23).

Tomar as observações de Constant sobre a história da Grécia ou de Roma como ponto central de sua argumentação pode levar-nos a trilhar um caminho falso. Se a menção ao mundo antigo parece fundamental para ele, isso se deve muito mais a seu desejo de afirmação da particularidade dos tempos que estava vivendo e à sua vontade de demarcar o terreno próprio da modernidade do que a uma visão acurada dos tempos antigos. Basta acompanhar seu texto para ver que demarcar fronteiras impossíveis de serem ultrapassadas era muito mais
20 "Dans les republiques de Tantiguité, la petitesse du territoire faisait que chaque citoyen avaitpolitiquementune grande importance" |Beniamin Constant, "De l'Esprit de Conquête et de l'Usurpation" op. cit., p. 182

$21 \mathrm{ldem}$, ibidem, p. 183

22 No verbete 0 autor analisa 0 caso de Atenas como um dos mais importantes, ao lado de Roma, para a compreensão da noção de república na Antigüidade.

23 Benjamin Constant, "De la Liberté des Anciens Comparée à Celle des Modernes", op cit., p. 507. 
24 Benjamin Constant, "De l'Esprit de Conquête et de I'Usurpation", op. cit., p. 185

25 ldem, ibidem, p. 186.

26 ldem, ibidem, p. 187

27 Benjamin Constant, "De la Liberté des Anciens Comparée à Celle des Modernes", op. cit. p. 505 .

28 Benjamin Constant, "De l'Esprit de Conquête et de I'Usurpation", op. cit., p. 191.

29 ldem, ibidem.

30 Supostamente a referência de Constanté ao capítulo XXVI do primeiro livro dos Discors (Machiavel, "Discorsi sopra la Prima Deca di Tito Livio", in Tutte le Opera, Firenze, Sansoni,
1971, p. 1091. Como já observou Gauchet, a passagem citada simplesmente não existe. Lendo o capítulo, constatamos, aliás, que ela não reflete em nada o espírito do mesmo ou o tema tratado pelo autor florentino. importante do que realizar um estudo cuidadoso do passado. $\mathrm{O}$ verdadeiro motivo para citar o mundo antigo era mostrar que estamos a uma grande distância dele, inclusive no plano moral. Como afirma nosso autor: "os antigos estavam na juventude da vida moral, nós estamos na maturidade, talvez mesmo na velhice; carregamos conosco sempre um pensamento escondido que desfaz o entusiasmo" (24). Qualquer qualidade associada aos antigos devia ser descartada da vida pública, pelo simples motivo de que a marcha da história a tinha tornado algo impossível de ser realizada nos tempos presentes.

A continuação da leitura do texto pode nos fornecer elementos preciosos para a compreensão das disputas envolvidas nas posições assumidas por Constant. Para o leitor atual cabe, no entanto, notar que, se podemos ser sensíveis à acuidade das observações de nosso autor a respeito da natureza das sociedades modernas, não podemos deixar de lado o fato de que ele pretende fundamentá-las em uma visão acanhada da Antigüidade e numa noção bastante arraigada quanto à marcha da história. Nesse sentido, não vemos razão para aceitar sem mais a distinção entre o mundo moral dos antigos e o mundo dos modernos, se não estivermos dispostos ao mesmo tempo a adotar as razões que fundamentam a argumentação de Constant. Isso não tem nada a ver com o reconhecimento da distância que nos separa da Antiguiidade e com o fato óbvio de que não podemos, sobretudo hoje, pretender repetir suas práticas no mundo moral e político. A constatação da distância entre as diversas experiências históricas não prova que os argumentos de Constant devem ser aceitos sem maiores problemas. De nossa parte, acreditamos que somente o acompanhamento do texto pode nos levar a deslindar a verdadeira batalha travada por nosso autor. Como mostraremos, ela tinha pouca relação com uma visão correta do mundo antigo e de seus desenvolvimentos.

O começo do sétimo capítulo da segunda parte do texto que estamos analisando dirige nosso olhar para o verdadeiro objeto de crítica de Constant: a Revolução Fran- cesa e seus atores. Partindo do que fora dito antes, ele afirma: "Essas verdades foram completamente desconhecidas pelos homens que, no final do século passado, acreditaram que deviam regenerar a humanidade" (25). A explicação mais óbvia para isso era o fato de que os homens da revolução adotaram a obra de Rousseau como referência e fizeram dela um manual que os conduziu, e só podia fazê-lo, diretamente à tirania. Esse será o grande tema de vários escritos de nosso autor. "Veremos", diz ele, "[...] que a metafísica sutil do Contrato Social só serve em nossos dias para fornecer as armas e os pretextos para todos os tipos de tirania" (26). Ao lado de Mably, o filósofo de Genebra será o alvo privilegiado dos ataques de Constant. Para ele: "Os homens, que foram levados pela onda dos acontecimentos a liderar nossa revolução, estavam, em conseqüência da educação que haviam recebido, imbuídos das opiniões antiquadas e tornadas falsas, que os filósofos de que falei haviam posto em realce" (27). O Contrato Social de Rousseau será visto como a obra matriz de uma visão passadista da história, que via na continuidade absurda entre os tempos antigos e a modernidade a ponte entre uma liberdade política real e uma ficção que, nas condições do capitalismo nascente, só podia conduzir a um feroz despotismo.

A linha principal da argumentação de Constant consiste, portanto, na ligação íntima entre a obra de Rousseau, sua visão da Antigüidade e o fato de que os revolucionários fizeram dessas constatações a mola para uma série de ações, que não podiam resultar em outra coisa a não ser em uma tirania. "Os partidários da liberdade antiga ficaram furiosos com o fato de que os modernos não queriam ser livres de acordo com o método que escolheram" (28). Para alcançar seus objetivos, serviram-se de uma máxima, atribuída a Maquiavel segundo a qual "Pela tirania é preciso mudar tudo" (29). Pouco importa, aqui, que tal máxima não se encontra em Maquiavel (30), ou que nosso autor não se preocupe em demonstrar a fundamentação da "sutil metafísica" de Rousseau. Tal análise certamente mostraria a fragilidade da 
leitura realizada por Constant das obras dos dois autores, mas mascararia o verdadeiro objetivo de seus escritos, que tiveram sempre a pretensão de influenciar diretamente o debate político, e não de servir como referência à compreensão erudita dos escritos dos filósofos que critica de maneira veemente. Rousseau, em particular, interessa porque foi o criador intelectual do jacobinismo, não por sua vontade, mas por seus erros e enganos quanto à natureza dos tempos e dos homens. O que deve ser combatido é o par formado pela união entre Rousseau e Robespierre que, por seus delírios com relação à natureza da liberdade possível nos tempos modernos, conduziram os homens a novos sofrimentos.

Constant foi, como mostra a parte final de sua conferência de 1819, um defensor do sistema parlamentar inglês, e se transformou num dos críticos do republicanismo que sempre associou ao jacobinismo. Suas críticas tanto à república e à revolução ecoaram ao longo de todo o século XIX. Como mostra Claude Nicolet em seu clássico L'Idee Republicaine en France (31), de sua pena partiram os toques iniciais de uma oposição entre o republicanismo francês e o liberalismo inglês, que ganharia contornos muito variados ao longo do século XIX. Nesse sentido, a obra de Constant é de fato um marco do pensamento liberal moderno, mas também o ponto de partida de uma argumentação em muitos aspectos falaciosa.

No curso do século que se seguiu à Revolução Francesa, Rousseau continuou a exercer uma grande influência sobre os pensadores que procuraram dar forma à idéia de vontade geral, assim como sobre aqueles que procuravam negar a validade da experiência republicana iniciada com a Revolução Francesa. A idéia de que o mundo antigo podia servir como referência para se pensar a política sobreviveu até mesmo entre pensadores como Gambetta e Ferry (32) que, embora marcados pelo pensamento anglo-saxônico, ainda faziam referência à experiência de Atenas para provar que a implicação dos indivíduos diretamente na vida pública era algo desejável e saudável para o estabelecimento de uma república que fosse outra coisa do que aquela sonhada e implementada pelos homens da última década do século XVIII e que, segundo Constant, haviam tentado obrigar seus contemporâneos a serem livres como antigamente.

A relação entre a crítica liberal e o pensamento de Rousseau é um dos temas mais visitados pela crítica especializada. Há quase dois séculos os defensores das duas posições trocam farpas e acusações sobre um terreno de mútua incompreensão. Nesse campo minado não seria difícil mostrar o quão redutora é a leitura feita dos textos do filósofo genebrino por seu crítico liberal mais conhecido na França. De fato, Constant não se preocupa nem um pouco em definir o estatuto teórico de noções como a de "vontade geral" e nem de investigar o papel que de fato a Antiguiidade tinha na obra de Rousseau (33). Defensor ardoroso da ruptura inequívoca com o passado mais distante, não hesita em dizer que o "espírito cavalheiresco" deveria ser conservado na modernidade, pois "o uso de formas doces e o hábito das nuanças engenhosas dão à alma uma susceptibilidade delicada, ao espírito uma flexibilidade rápida" (34). Crítico das virtudes cívicas, Constant é nostálgico das sociedades de corte nas quais brilhava o "belo espírito". Distante da argúcia de Tocqueville, que soube compreender as verdadeiras dificuldades impostas àqueles que desejam mudar inteiramente o governo dos homens e seus vínculos com a tradição (35), Constant se contentou muitas vezes com a simples constatação de que a modernidade havia forjado um caminho distante das antigas práticas, sem se preocupar com a multiplicidade de sendas que se abriam com essa nova era.

Retornar, no entanto, aos debates sobre a relação entre os dois pensadores não seria um procedimento cabível no espaço de um artigo. Para nossos propósitos, cabe lembrar que a leitura dos escritos de Constant permite que apreciemos ainda hoje alguns de seus méritos. No começo do século XIX, acuado por um desejo incontrolável de sucesso e por uma situação política que não o favorecia, ele percebeu, com uma clareza
31 Claude Nicolet, L'Idée Républicaine en France (1789 19241. Paris, Gallimard 1994, pp. 70-4

32 ldem, ibidem, p. 481.

33 A esse respeito é interessante consultar: Denise Leduc Fayette, I. - Rousseau et Mythe de l'Antiguité, Paris, J. Vrin, 1974

34 Beniamin Constant, "De l'Esprit de Conquête et de l'Usurpation", op. cit., p. 193.

35 Tocqueville, L'Ancien Regime et la Révolution, Paris, Garnier Flammarion, 1988, Cap. XII pp. $211-27$ 
muitas vezes ausente em seus contemporâneos, que a grande novidade revolucionária deveria ser medida por parâmetros totalmente distintos daqueles empregados pelos homens que participaram diretamente dos acontecimentos decisivos da Revolução Francesa. Reconhecendo o papel central dos indivíduos nas sociedades modernas e o aparecimento dos mecanismos de representação como parte integrante de um novo tempo, Constant não fez mais do que mergulhar na corrente de pensadores que buscavam se distanciar dos paradigmas da Antigüidade, mas soube produzir um referencial teórico interessante para julgar os acontecimentos que estiveram no centro de sua existência (36).

O que nos cabe perguntar, no entanto, é se o reconhecimento dos méritos de Constant permite-nos adotar seu diagnóstico das sociedades modernas, em particular no tocante ao problema da liberdade, como pertinente para todas as situações envolvendo a participação dos indivíduos na vida pública, sobretudo nos dias de hoje. Essa parece ser a tendência de muitos escritores, como vimos, que aceitam sem mais a distinção entre liberdade negativa e liberdade positiva como um dado das sociedades contemporâneas. A suposta demonstração da incompatibilidade moderna com a participação dos cidadãos na vida pública é tomada como um dado natural a ser incorporado sem mais aos diagnósticos que traçamos de nossos problemas.

Ora, a análise dos principais argumentos empregados por Constant, para sustentar sua posição quanto à questão da liberdade, sugere que eles não são necessariamente um instrumento eficaz para pensar o problema da liberdade e da natureza das sociedades democráticas na atualidade. Se a leitura de nosso autor pôde ser inovadora no momento em que foi realizada, isso não implica dizer que seja um diagnóstico válido para além do momento em que foi formulado. O que procuramos mostrar, na verdade, é que, mesmo em seu tempo, a obra de Constant padecia de algumas fragilidades, que traíam a mistura entre as motivações de seus combates políticos pesso- ais e sua maneira de conceber a modernidade. A priori isso não tem nada de errado, pois quase todos os grandes pensadores políticos modernos se viram envolvidos nas disputas políticas de sua época e foram marcados por elas, quando passaram a refletir sobre a natureza das sociedades em que viviam. O que importa reter, entretanto, é a fundamentação de seus argumentos, as razões que os sustentam, e isso independente dos méritos que eventualmente conservam ao longo dos anos.

No caso de Constant, o que gostaríamos de conservar é o fato de que sua interpretação da liberdade moderna como sendo essencialmente ausente de constrangimentoé solidária com uma visão do progresso e sua incompreensão da complexidade do fenômeno revolucionário, ainda que tenha sido capaz de deslindar seus aspectos mais perversos. Ele não viu, e não poderia ter visto, que os ideais republicanos nascidos na Revolução gestariam uma tradição de reflexão política, que iria muito além da apropriação por Robespierre do pensamento de Rousseau. Por outro lado, sua adoração do mundo inglês o cegou para a extraordinária experiência norte-americana e para as questões fundamentais que suscitam, como mostrará Tocqueville. Um segundo aspecto que cabe anotar é que, para tornar coerentes seus argumentos, Constant foi obrigado a retratar os indivíduos contemporâneos como mônadas, alheios, em sua busca de satisfação pessoal, a toda participação no mundo público que não fosse pelos mecanismos de representação. Os que se aventuraram para fora dessa cápsula de isolamento se viram diante da tarefa impossível de resgatar as virtudes dos heróis da Antigüidade num mundo que já não tinha espaço para isso. $\mathrm{O}$ resultado dessa vontade por vezes generosa foi, aos olhos do pensador liberal, a sujeição de todos os que se negaram a reconhecer o mérito da empreitada.

Se Constant permanece uma referência para se compreender o desenvolvimento do pensamento liberal ao longo do século XIX na França, a apropriação de sua distinção entre as duas formas de liberdade no contexto atual parece-nos bastante problemática. 
Em primeiro lugar, não podemos deixar de lado o fato de que a crítica ao mito da Antigüidade feita por nosso autor em sua época não conserva nenhuma pertinência em nosso tempo. Ninguém pensa hoje seriamente em recorrer aos exemplos romanos para discutir problemas sobre a participação política, senão para usar como metáfora ou outro recurso de expressão. Na verdade, seria interessante retornarmos a autores como Rousseau para verificarmos se de fato a Antigüidade era para eles um motivo de adoração irrefletida. De nossa parte, tenderíamos a negar essa hipótese, mas sua demonstração nos conduziria para muito longe de nossos objetivos. O que nos importa é que pensadores como Berlin recuperam as críticas ao ideal de liberdade positiva como se ele pudesse ter se mantido o mesmo ao longo de mais de duzentos anos. Repetindo a operação conceitual de Constant, que realizava sem mediações a ponte entre o pensamento de Rousseau, o terror jacobino e as aspirações republicanas, Berlin e outros reduzem o campo dos debates a uma disputa entre uma visão passadista do papel das virtudes cívicas e a afirmação do papel central do individualismo na construção das sociedades políticas contemporâneas. O que é deixado de lado nessa maneira de abordar o problema é que ela é solidária de uma visão da história como progresso e de uma antropologia que descreve o homem primordialmente a partir de seus interesses e apetites. Sem a discussão desses fundamentos teóricos ficaremos reduzidos ao mero embate ideológico opondo partidários da participação política e epígonos da apatia.

Ora, nãoprecisamos necessariamente nos servir da figura do herói antigo ou de seu sucedâneo revolucionário (37) para pensarmos o papel dos atores políticos em nossas sociedades. Se os pensadores liberais têm razão em recusar a lógica que presidiu a ação dos homens que instituíram o terror em nome da vontade geral, nada prova que essa seja a lógica de toda e qualquer participação direta dos cidadãos na cena pública. Para que essa abordagem do problema funcione, é preciso aceitar a amálgama operada por Berlin entre todas as correntes políticas que não aceita- ramos pressupostos da tradição liberal. Esse procedimento não faz justiça nem aos pensadores que se dedicaram a enfrentar o desafio de construir um pensamento republicano ao longo dos últimos duzentos anos (38), nem à prática efetiva dos cidadãos, que em nome de ideais variados se dispuseram a atuar de forma direta na arena política nas muitas transformações que mudaram a face do mundo.

O que gostaríamos de afirmar é que, ao aceitarmos a caracterização da modernidade sugerida pelos herdeiros de Constant, estamos na verdade assumindo uma restrição dos termos do debate sobre a natureza das sociedades democráticas contemporâneas. A simples contraposição entre liberdade negativa e liberdade positiva não é uma chave fecunda para se pensar problemas complexos como o das virtudes cívicas, da participação política, da identidade constitucional ou do patriotismo. Isso pelo simples fato de que depende de pressupostos filosóficos, que não podem ser aceitos como princípios inquestionáveis e universais por todos os que se dedicam a pensar a natureza da vida política. Talvez seja mais fecundo reconhecer a complexidade da questão da liberdade na atualidade do que insistir na dicotomia elaborada no final do século XVIII. Entre a república dos antigos e a república dos modernos existe sim uma ruptura decisiva, mas nada nos impede de nos servir do passado para pensar a identidade de nossas formações sociais. $\mathrm{O}$ desaparecimento completo da cena pública das referências ao mundo antigo ajudanos a formular o problema da liberdade, da natureza da cidadania, da participação política e da representação em termos muito diferentes do que aqueles sustentados por Constant e por todos os que se serviram de sua herança para defender uma visão acanhada das possibilidades da vida política na contemporaneidade. O grande desafio diante do qual a tradição republicana se encontra é justamente dizer qual liberdade é possível em sociedades que são o fruto do longo e doloroso processo de gestação da modernidade e não do gesto irrefletido de adoração da república dos antigos.

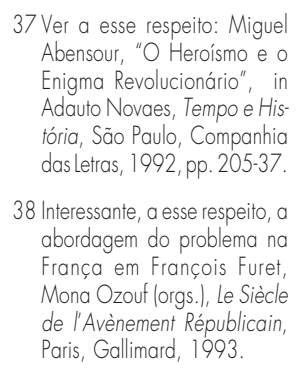

